\title{
Diabetes insipidus with impaired osmotic regulation in septo-optic dysplasia and agenesis of the corpus callosum
}

\author{
N Masera, D B Grant, R Stanhope, M A Preece
}

\begin{abstract}
The clinical and endocrinological findings in 24 children with septo-optic dysplasia and/or agenesis of the corpus callosum are described with particular reference to posterior pituitary function. Nine had diabetes insipidus. The prevalence of diabetes insipidus was similar in children with complete and incomplete forms of septo-optic dysplasia. Maintenance of normal osmotic balance was very difficult in six of these children, even after the introduction of treatment with vasopressin, either as desmopressin, or lysine vasopressin spray in one of the early cases.
\end{abstract}

(Arch Dis Child 1994; 70: 51-53)

The association between congenital optic nerve hypoplasia and absence of the septum pellucidum was first described by Reeves in a 7 month old child. ${ }^{1}$ de Morsier confirmed the association in 1956 and suggested the term septo-optic dysplasia which has now been widely adopted. ${ }^{2}$ Hoyt $e t$ al reported the association of optic nerve hypoplasia, abnormal septum pellucidum, and deficiency of both anterior and posterior pituitary function. ${ }^{3}$ It has become apparent that the three individual defects variably related to one another in the syndrome of septo-optic dysplasia represent one extreme of a wider spectrum of abnormalities of holoprosencephaly with single cerebral ventricle and absence of the corpus callosum, among other midline defects.

While anterior pituitary deficiency in septooptic dysplasia has been well documented, ${ }^{4-7}$ diabetes insipidus has been reported less often and there is little information on the control of osmotic equilibrium in such patients. As our own observations have suggested that disordered osmotic homoeostasis may be quite common in children with septo-optic dysplasia, we have carried out a retrospective study on 24 children seen in the endocrine clinics at this hospital between 1971 and 1992.

Institute of Child

Health, London

N Masera

D B Grant

R Stanhope

M A Preece

Correspondence to: Dr D B Grant, The Hospital for Sick Children, Great WCIN 3JH.

Accepted 16 September 1993

\section{Subjects and methods}

SUBJECTS

The casenotes of 24 children with septo-optic dysplasia and/or agenesis of the corpus callosum were available for review. Eight children were considered to have the complete form of the syndrome (optic nerve hypoplasia, abnormal septum pellucidum, and pituitary deficiency) and 13 to have incomplete forms (two elements of the three). One child with complete septo-optic dysplasia and one with incomplete septo-optic dysplasia also had agenesis of the corpus callosum and three further children had isolated agenesis of the corpus callosum with pituitary deficiency. One child with septo-optic dysplasia was also a mosaic for Turner's syndrome ( $85 \%$ XO; $15 \%$ $\mathrm{XX}$ ). The age at diagnosis ranged from 2 weeks to 8.8 years (mean 2.0 years) and the age at last follow up ranged from 1 to 17 years. Seven children were completely blind and eight had severe visual impairment. Thirteen showed either moderate or severe developmental delay.

\section{METHODS}

Pituitary function was assessed using standard methods. ${ }^{8}$ Insulin induced hypoglycaemia or glucagon tests were carried out to evaluate growth hormone and adrenocorticotrophic hormone (ACTH) secretion in all cases. Estimation of plasma thyroxine and thyroid stimulating hormone (TSH) in all children (with thryoid releasing hormone stimulation in 15 cases) was used to assess pituitary TSH secretion; gonadotrophin secretion was assessed after injection of gonadotrophin releasing hormone (GnRH) in 14 cases. In 12 cases standard water deprivation tests were carried out. ${ }^{8}$

In all cases cranial computed tomography was performed to assess the midline structural abnormality.

\section{Results}

Overall, growth hormone insufficiency was present in 20 of the 24 cases, and 14 of these children have been treated with human pituitary or recombinant growth hormone. ACTH deficiency was documented in 15 cases. Gonadotrophin deficiency was demonstrated in 10 of the 14 cases tested with GnRH.

Nine children had diabetes insipidus. Seven of these children were completely blind or had severely restricted vision, seven had moderate or severe mental retardation, and four had one or more episodes of hypoglycaemia in early infancy (table). Details of the computed tomography findings, osmolar impairment, and other endocrine deficits are also given in the table. Three children presented with failure to thrive and hypernatraemia within two months of birth, and four more with hypernatraemia before the age of 1 year. In one child (case 8 ) there was no clinical evidence of 
Clinical, neuroanatomical, biochemical, and endocrine findings in nine children with diabetes insipidus

\begin{tabular}{|c|c|c|c|c|c|c|c|c|c|}
\hline & \multicolumn{9}{|c|}{ Case No } \\
\hline & 1 & 2 & 3 & 4 & 5 & 6 & 7 & 8 & 9 \\
\hline $\begin{array}{l}\text { Clinical features } \\
\text { Sex } \\
\text { Age at diagnosis of diabetes insipidus }\end{array}$ & F & $\mathbf{M}$ & $\mathbf{M}$ & $\mathrm{F}$ & $\mathbf{M}$ & $\mathrm{F}$ & $F$ & F & $\mathrm{F}$ \\
\hline $\begin{array}{l}\text { in months }(\mathrm{m}) \text { or years }(\mathrm{y}) \\
\text { Severe visual impairment } \\
\text { Moderate/severe mental retardation } \\
\text { Inappropriate sense of thirst } \\
\text { Hypoglycaemia in infancy }\end{array}$ & $\begin{array}{l}1.5 \mathrm{~m} \\
+ \\
- \\
- \\
-\end{array}$ & $\begin{array}{l}9 \mathrm{~m} \\
+ \\
+ \\
+ \\
+\end{array}$ & $\begin{array}{l}2 \mathrm{~m} \\
+ \\
+ \\
- \\
+\end{array}$ & $\begin{array}{l}7 \mathrm{~m} \\
+ \\
- \\
- \\
+\end{array}$ & $\begin{array}{l}3 \mathrm{~m} \\
+ \\
+ \\
+ \\
-\end{array}$ & $\begin{array}{l}2 \mathrm{~m} \\
- \\
+ \\
+ \\
-\end{array}$ & $\begin{array}{l}3 \mathrm{~m} \\
+ \\
+ \\
+ \\
+\end{array}$ & $\begin{array}{l}8 y \\
- \\
+ \\
-\end{array}$ & $\begin{array}{l}5 y \\
+ \\
+ \\
+ \\
-\end{array}$ \\
\hline $\begin{array}{l}\text { Abnormal neuroanatomy } \\
\text { Absent septum pellucidum } \\
\text { Optic nerve hypoplasia }\end{array}$ & $\begin{array}{l}+^{\star} \\
+\end{array}$ & $\bar{t}$ & $\begin{array}{l}+ \\
+\end{array}$ & - & $\bar{t}$ & + & - & + & $\begin{array}{l}+ \\
+\end{array}$ \\
\hline $\begin{array}{l}\text { Osmolar impairment } \\
\text { (on treatment with vasopressin) }\end{array}$ & & & & & & & & & \\
\hline $\begin{array}{l}\text { Hypernatraemia } \\
\text { Hyponatraemia }\end{array}$ & $\overline{-}$ & $\begin{array}{l}-\ddagger \\
+\ddagger\end{array}$ & $\overline{-}$ & $\overline{+}+$ & $\begin{array}{l}+ \\
+\ddagger\end{array}$ & $\begin{array}{l}+ \\
-\end{array}$ & $\begin{array}{l}+ \\
+\ddagger\end{array}$ & $\begin{array}{l}- \\
-\end{array}$ & $\overline{+}+$ \\
\hline $\begin{array}{l}\text { Other endocrine deficits } \\
\text { Growth hormone } \\
\text { ACTH } \\
\text { TSH }\end{array}$ & $\begin{array}{l}+ \\
+ \\
+\end{array}$ & $\begin{array}{l}+ \\
- \\
-\end{array}$ & $\begin{array}{l}+ \\
+ \\
+\end{array}$ & $\begin{array}{l}+ \\
+ \\
+\end{array}$ & $\begin{array}{l}- \\
\overline{+}\end{array}$ & $\begin{array}{l}- \\
+ \\
-\end{array}$ & $\begin{array}{l}+ \\
+ \\
+\end{array}$ & $\begin{array}{l}+ \\
+ \\
+\end{array}$ & $\begin{array}{l}+ \\
+ \\
+\end{array}$ \\
\hline
\end{tabular}

$\star$ Also absent corpus callosum. $†$ No long term treatment with vasopressin. $¥$ Hyponatraemia associated with seizures and impaired consciousness.

diabetes insipidus until the age of 5 years when she was admitted to hospital with dehydration and hypernatraemia. A water deprivation test at that time resulted in a maximum urine osmolality of $612 \mathrm{mmol} / \mathrm{kg}$ and this was interpreted as indicating incomplete vasopressin deficiency. Because of persistent hypernatraemia, she was started on lysine vasopressin which was subsequently changed to desmopressin (DDAVP, Ferring). One child (case 9) had polydipsia from early infancy but the diagnosis of diabetes insipidus was only established at the age of 8.5 years when she was started on high dose steroid treatment after cerebral oedema due to iatrogenic hyperglycaemia after an insulin hypoglycaemia test for growth hormone deficiency. ${ }^{9}$

Five children (cases 2, 5, 6, 7, 9) appeared to have an impaired sense of thirst in the presence of hypernatraemia; three of these patients continued to show intermittent hypernatraemia despite treatment with vasopressin and two of them (cases 6 and 9) died at the ages of 2.9 and 5.7 years after acute infections associated with severe dehydration. Five patients (cases 2, 4, 5, 7, 9) had one or more admissions with seizures and impairment of consciousness associated with mild hyponatraemia while on treatment with vasopressin.

\section{Discussion}

While we are aware of 15 cases of diabetes insipidus reported in children with septooptic dysplasia or agenesis of the corpus callosum, ${ }^{6} 7_{10-15}$ there is little information on either the prevalence of diabetes insipidus or on the maintenance of normal osmotic equilibrium in such patients. In the present study we found that the overall prevalence of diabetes insipidus was $38 \%$ and that disturbance of fluid balance was a significant problem in several of the cases. There was little correlation between the clinical features and the structural central nervous system lesions; $78 \%$ of the cases with diabetes insipidus had incomplete forms of septo-optic dysplasia, as compared with $60 \%$ of those without diabetes insipidus.
The management of diabetes insipidus was difficult in several cases and five required two or more admissions to hospital in an attempt to stabilise their daily fluid balance with appropriate doses of desmopressin or lysine vasopressin. A number of factors probably contributed to this difficulty. First, several children appeared to have impairment of their sense of thirst. This, together with their dependence on their parents for water and food as a result of their blindness and developmental delay, probably accounts for much of the difficulty.

It is not clear whether the mental retardation commonly seen in septo-optic dysplasia is a consequence of abnormal brain development or whether it is due to other factors, for example, hypoglycaemia or repeated episodes of electrolyte imbalance that may contribute to further neurological damage. In particular, rapid correction of hyponatraemia may be associated with central pontine myelinolysis that can also involve the basal nuclei and central white matter causing quadriplegia, mental retardation, and sometimes cranial nerve dysfunction. ${ }^{16}$ Psychosocial deprivation, which in our experience is quite common in such children, may also play a part in the developmental delay, and possibly in the abnormal growth hormone secretion. ${ }^{17}$

In conclusion, in our experience diabetes insipidus is a relatively common finding in patients with the complete and incomplete forms of septo-optic dysplasia and management of fluid balance can be difficult in such patients, particularly if they have an impaired sense of thirst.

1 Reeves DL. Congenital absence of the septum pellucidum. Bulletin of fohns Hopkins Hospital 1941; 69: 61-71.

2 de Morsier G. Etudes sur les dysraphies cranioencephaliques: III Agenesis du septum lucidum avec malformation du tractus optique. Schweizer Archive fur Neurologie Neurochirurgia und Psychiatrie 1956; 77: 267-92.

3 Hoyt WF, Kaplan SL, Grumbach MM, Glaser JS. Septooptic dysplasia and pituitary dwarfism. Lancet 1970; i: 893-4.

4 Billson F, Hopkins IJ. Optic hypoplasia and hypopituitarism. Lancet 1972; i: 905.

5 Krause-Bruckner W, Gardner DW. Optic nerve hypoplasia associated with absent septum pellucidum and hypopituitarism. Am f Ophthalmol 1980; 89: 113-20.

6 Stanhope R, Preece MA, Brook CGD. Hypoplastic optic nerves and pituitary dysfunction. Arch Dis Child 1984; 59: $111-4$. 
7 Morishima A, Aranoft GS. Syndrome of septo-optic-pituitary dysplasia: the clinical spectrum. Brain Dev 1986; 8: 233-9.

8 Clayton BE, Jenkins P, Round JM. Paediatric chemical pathology. Clinical tests and reference ranges. London: Blackwell Scientific Publications, 1980.

9 Shah A, Stanhope R, Matthew D. Hazards of pharmacological tests of growth hormone secretion in childhood: logical tests of growth

10 Igarishi N, Kyoya S, Ichida F, Sato T. Inappropriate ADH secretion and essential hypernatraemia in an infant with hocretion and essential hypernatraemia in an infant with
1991; 4: 111-4. Fournal of Pediatric Endocrinology

11 Freude S, Frisch H, Wimberger D, et al. Septo-optic dysplasia and growth hormone deficiency: accelerated pubertal maturation during GH therapy. Acta Paediatr 1992; 81: 641-5.

12 Yukizane S, Kimura Y, Yamashita Y, et al. Growth hormone deficiency of hypothalamic origin in septo-optic dysplasia. Eur f Pediatr 1990; 150: 30-3.
13 Kaplan SL, Grumbach MM, Hoyt WF. A syndrome of hypopituitary dwarfism, hypoplasia of the optic nerves and malformation of the prosencephalon: report of 6 patients. Pediatr Res 1970; 4: 480-1.

14 Roessman U, Velasco ME, Small EJ, Hori A Neuropathology of septo-optic dysplasia (de Morsier syndrome) with immunohistochemical studies of the hypothalamus and pituitary gland. $f$ Neuropathol Exp Neurol 1987; 46: 597-608.

15 Margalith D, Tze WJ, Jan JE. Congenital optic nerve Margalith D, Tze WJ, Jan JE. Congenital optic nerve
hypoplasia with hypothalamic-pituitary dysplasia: a review hypoplasia with hypothalamic-pituitary dysplasia:

16 Aicardi J. Electrolyte and acid-base metabolism disturbances, nutritional disorders and other systemic diseases. Diseases of the nervous system in childhood. London: MacKeith Press, 1992: 1241-4.

17 Powell GF, Brasel JA, Raiti S, Blizzard RM. Emotional deprivation and growth retardation simulating idiopathic hypopituitarism. N Engl 7 Med 1967; 276: 1279-83. 